\title{
Morphometry as a Method of Studying Adaptive Regulation of Embryogenesis in Polluted Environments
}

\author{
Elena A. Severtsova, David R. Aguillón Gutiérrez \\ and Aleksey S. Severtsov \\ Lomonosov Moscow State University \\ Russian Federation
}

\section{Introduction}

Amphibians- one of the most convenient natural objects to study the effect of various pollutants (Dawson et al, 1985). They are very sensitive to changes in the environment. Larval and adult specimens have a high permeable skin and their life cycle takes place in water and in terrestrial ecosystems, depending on the stage of the life cycle; they have different types of food; their special reproduction allows monitoring of development and the quantity to conduct representative research (Cooke, 1974; Greenhouse, 1976; Sparling et al, 2001).

In addition, some amphibian species are laboratory animals with a well-studied biology and genetics, for example the clawed frog (Xenopus laevis), which is the biological model in the FETAX project (Fort et al, 2004; Morgan et al, 1996) and Xenopus metamorphosis assay (XEMA) (Opitz et al, 2005) which conducted test of various chemical pollutants. Applied nature of these programs involves testing the impact on the embryogenesis of each substance alone (FETAX, 1991), although in nature, in the embryo affects a complex of pollutants of the lake. Therefore, in recent years, within the confines of FETAX system, are conducted analyzes of the synergistic complex of pollutants (Orton et al., 2006; Ettler et al., 2008), which allows to evaluate the natural biotoxicity and anthropogenic pollutants.

However, being just test models, laboratory animals because of its unsuitability to the full range of factors in nature, can not be regarded as indicators of ecosystem pollution. Thus, the experimental exposure to pesticides (particularly DDT [dichlorodiphenyltrichloroethane] and $\mathrm{HCH}$ [Hexachlorocyclohexane]) on eggs of Clawed and Moor frogs, showed significantly more sensitive reaction in Xenopus laevis than natural populations of Rana arvalis, making an incorrect comparative analysis (Voronova et al, 1983).

Therefore, to study the effects of pollution in natural habitats are more informative the representatives of natural populations (Stroganov, 1971). Field studies are conducted on widely distributed amphibian species: Rana pipens (Allran \& Karasov, 2000, 2001), Rana arvalis (Andren et al, 1989), Rana temporaria (Leontieva \& Semenov, 1997; Dunson et al, 1992; Johansson et al, 2001), Bufo americanus (Hecnar, 1995) and other species which by 1992 had 
already been tested 211 types of pollutants in 45 amphibian species (Hall \& Henry, 1992). Among these works dominates the studies on tadpoles or adult animals (Vershin, 1997; Freda, 1986; Horne \& Dunson, 1995). Typically, field studies are limited to the proportion of those who died and/or are abnormal embryos (Beattie et al, 1991). This is certainly an important indicator of overall population status, but, in our view, insufficient because they do not reflect the actual adaptation processes in natural populations under the action of a new environmental evolutionary factor (Vershinin, 1997; Severtsova, 2002), and is an indicator of only a fraction of genotypes who dropped out of population diversity. More informative is the method of morphometric evaluation of the nature of variability (Severtsova \& Severtsov, 2005).

\section{Morphometric analysis of early development}

The object of developmental studies is the development of the individual, whereas the subject of population studies - the aggregate of individuals united in a population. These two lines of research have traditionally developed independently. In the analysis of specimens is estimated the condition of the body at a certain stage of development and its dynamics in time and space. The study of ontogeny itself, which often is limited to embryonic development and identify differences between individuals.

In the study of population is estimated the populations status in a determinate moment and also its dynamics in time and space, it means the assessment of population dynamics and detection of inter and intrapopulation differences. This is usually not taken into account that each individual is ontogeny, and the population estimate is a slice of the trajectories of individual development. In those cases where this is taken into account the possible ontogenetic change as something that interferes with population estimate, and the problem usually comes down to their elimination by the analysis of individuals of the same age. At the same time as a special analysis of individual ontogeny is not only necessary for the correct assessment of populations and their dynamics in time and space, but also for understanding the mechanisms of the stability of population processes.

Stabilized development is one of the most common characteristics of the developing organism. It was shown that high stability is maintained on the basis of genetic coadaptation under optimal conditions of development (Zakharov, 1989; Moller \& Swaddle, 1997). A growing number of studies of developmental stability and incessant debate about the significance of such studies to characterize the state of the population determines the need to assess the possibility of using developmental stability as a measure of environmental stress for monitoring populations. In this case, the most convenient is the morphometric method based on an evaluation of morphological variability. Themselves morphometric methods for assessing variability are used frequently, including to assess the variability of synanthropic populations of animals and plants (see "Intraspecific variation ..." 1980; "Animals in ...", 1990, "Structure and functional role ...", 2001).

Assessment of variability in the earliest stages of development in this aspect was not carried out, although the method of study of their variability exists. Apparently, the quantitative study of the variability of morphogenetic traits was a Gurwitsch's idea (Gurwitsch, 1922: in Cherdantsev, 2003). The idea is that by studying the relation between the average and the variance of quantitative traits of the embryo or its parts, you can get a fairly accurate idea of 
the nature of interactions corresponding to the morphogenetic field. Specific studies on the Gurwitsch's planned program are very few (Cherdantsev \& Scobeyeva, 1994; Glukhova \& Cherdantsev, 1999; Severtsova, 2002), although this method can be used to study the variability of embryogenesis during the development in different contexts, including the anthropogenic pollution condition.

The model of some-like research is the most convenient anuran eggs at the stage of mid-late gastrula (Cherdantsev \& Scobeyeva, 1994), since the earlier stages are not enough informative, and the analysis of later stages must take into account a large number of complex processes, including those related to organogenesis. Gastrula stage is best studied in terms of morphogenetic processes and the genetic basis of regulation of these processes (Beetschen, 2001). In particular, revealed that in the analysis of morphological variability of gastrulation, in some amphibian species (Rana temporaria, Rana lessonae and Pelobates fuscus) there is huge value of the coefficients of variation of characters in the embryos that are genetically homogeneous (from the same clutch of eggs), developing in quite the same conditions, and the most importantly, developing normally in terms of the final result of embryonic development. It may be more than $50 \%$, ie almost an order of magnitude higher than normal variability of quantitative traits in definitive stages of development of the phenotype (see Falconer, 1981). In addition, is shown that this is the stage in early development of amphibians most sensitive to environmental effects (Saber \& Dunson, 1978; Beattie et al., 1992; Severtsova, 2005), that allows us to estimate the variability in the development stages, when the abnormality of the morphogenetic processes have not yet discernible to the naked eye.

For morphometric analysis, we selected the most popular anuran species in Moscow: Common frog (Rana temporaria L.), Moor frog (Rana arvalis Nills.) and the Marsh frog (Pelophylax ridibundus Pallas). In fixed eggs of these species were removed all the membranes, including the vitelline, made by standard embryological methods, divided sagittal and measured under a binocular microscope with eyepiece micrometer (accurate to 1 division of ocular micrometer; 20 divisions of ocular micrometer range $-1 \mathrm{~mm}$ ) following features (Fig. 1A): D1 - total diameter of the gastrula, D2 - diameter of yolk plug, ArthG roof height of gastrocele, $v$ h - the maximum height of the yolk duct, LbalD - the depth of the dorsal lip of blastopore screwing, LbalV - the depth of the ventral lip of blastopore screwing, $G$ - the distance between the deepest dorsal screwing and ventral blastopore lip, preg - the distance between the cavities of gastrocele and blastocele, ArthB - blastocoel roof height. The choice of these features provides a fairly complete description of gastrulation - one of the most important stages of embryogenesis (Slack et al., 1992; Gilbert, 1993; Cherdantsev, 2003). Such signs as LbalD, LbalV and G are key indicators of advanced gastrulation processes, as they reflect the extent and nature of the blastopore lip formation. ArthG - roof height of gastrocele - describes the process of forming chordomesoderm in the investigates development stage. Signs preg and $A r t h B$ are closely related to the previous stage of embryogenesis - blastulation, as they mark the location of the reducing blastocoel, and thus may serve, in conjunction with Arth G an index of "looseness" of the embryo. "Loose", commonly referred to the gastrula with non-dense intercellular contacts, or with abnormally large cells that do not allow because of the physical features of morphogenesis to form cavities or even to continue the further development (Cherdantsev, 2003). 
$1 \mathrm{~A}$

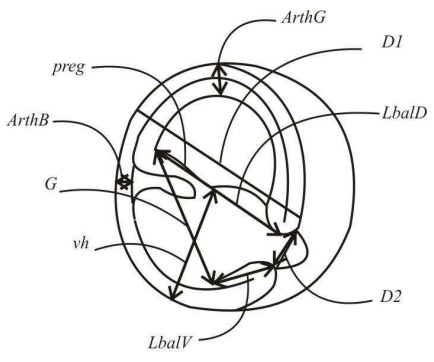

$1 \mathrm{~B}$

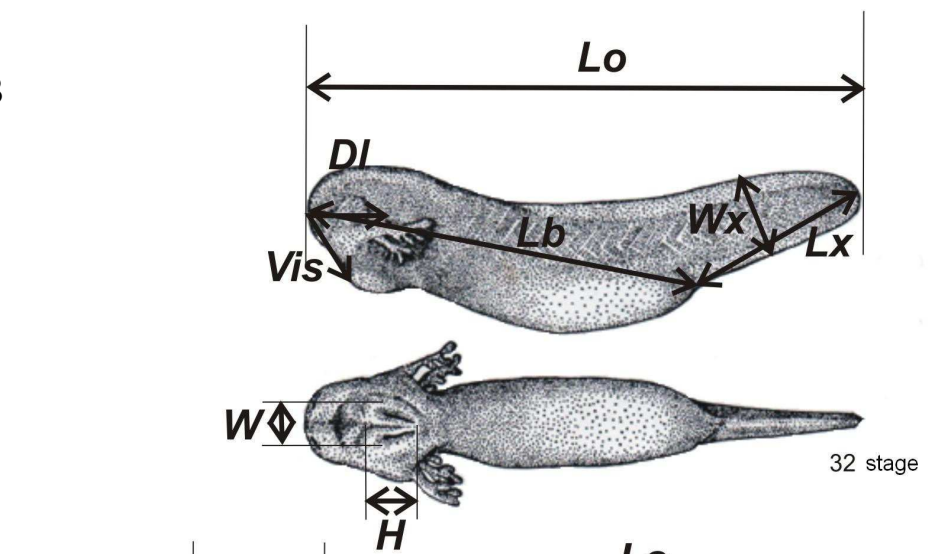

$1 \mathrm{C}$

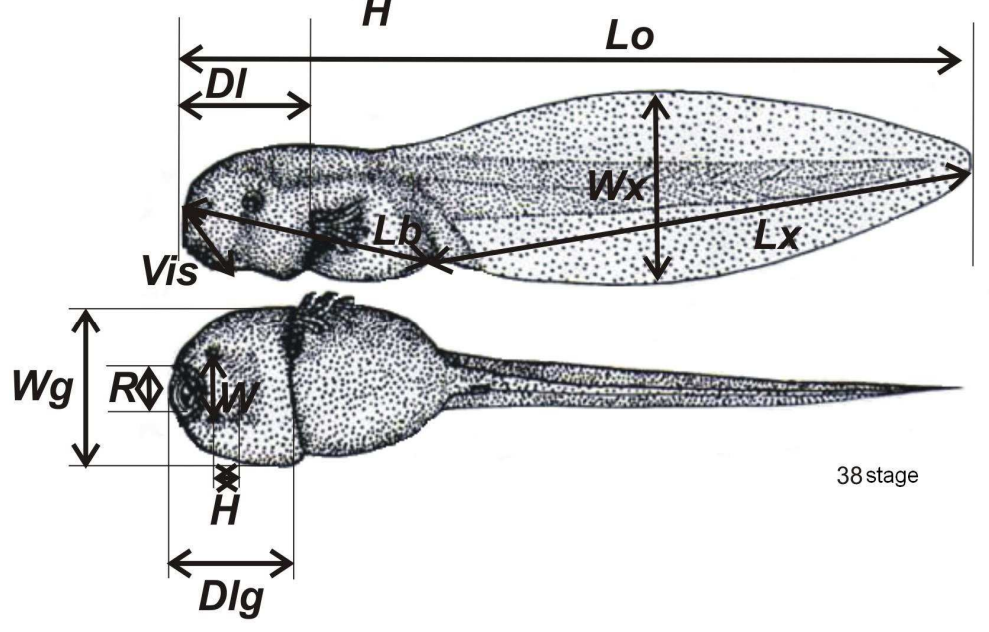

Fig. 1. Research of morphometrical signs. See notation in text.

Assessment of variability is possible at later stages of embryogenesis, for example at the stage of hatching larvae from the eggs (Fig. 1B). This stage of development is longer in comparison with gastrulation, but also allows to evaluate representatively the intrapopulation and intra-egg mass variability. Signs for the morphometric analysis are indicators such as: Lo- tadpole total length (from the outermost point of the snout to the tip 
of the tail plate); $L x$ - the length of the tail plate (from the cloaca to the tip of the tail plate); $\mathrm{Dl}$ - the length of the muzzle (from the base of the gill filaments to the outermost point of the muzzle); Vis - the height of the muzzle (from oral sucker to the outermost point of the muzzle); $W$ - width of oral sucker, $H$ - height of the oral sucker; $G$ - the number of gill filaments, summarized on the left and right sides of the embryo. In the analysis of development assessment is possible also include indices that reflect the proportional development of larvae. Correlation $L x$ / Lo - index of proportion of the tail plate's size relative to the total body length. Correlation $\mathrm{Dl} / \mathrm{Vis}$ is a measure of proportionality of head structures development. We considered the area of the oral sucker $\left(W{ }^{*} H\right) / 2$, as an indicator of the reliability of attachment when the tadpole had just hatched from the egg, where it is some time before moving on to the stage of free swimming. An indicator of the symmetry of the gill filaments development was like a asymmetry coefficient. At tadpole stages of development, including at the stage prior to the commencement of metamorphosis, the number of features can be extended (Fig. 1C), introducing measures such as the maximum width of the tail plate $(W x)$, head width $(W g)$ - the distance measured along the line of gill slits in the tadpole; the length of the head $(D l g)$ - the distance measured from the ventral surface of the tadpole through gills slits to the outermost point of the snout; sucker width $(W)$ - the distance between the sucker rollers; sucker heigh $(H)$ in the sagittal direction; mouth opening width $(R)$ - the distance between the corners of the mouth opening; the distance between the pupils of the eyes (eye). Evaluation of these indicators reflect the two most important processes: growth and differentiation. The same measurements can be made even in vivo, without damaging the tadpoles and without exerting a strong influence on the course of development. Last is the most valuable in studies aimed to studying the dynamics of development, including passing under the influence of various pollutants.

\section{Variability and correlation of early development}

One of the main parameters, with which operates the morphometric analysis - is the concept of "variability". From a biological point of view, it implies the diversity of individuals in the study group. Expressed mathematically in such quantities as the variance, standard deviation or coefficient of variation. The latter parameter is used in our studies because, as a dimensionless quantity allows the comparison of mixed-signs. No less important is the concept of "correlation", i.e. consistency of the emerging structures of the developing organism. Mathematically, the nature and strength of this mutual influence is expressed through the correlation coefficient calculated for the signs in the role of characteristics of structures.

The results of morphometric research of gastrula stage in three species of anurans: Common frog (Rana temporaria L.), Moor frog (Rana arvalis Nills.) and Marsh frog (Pelophylax ridibundus Pallas, «Rana ridibunda in fig. 2»), inhabiting the territory of Moscow (Russia) show the ratio between the variability and the correlation of the processes of morphogenesis, as a response to environmental degradation (Severtsova, Severtsov, 2005, 2007). At the same time such a change occurs in different areas in different ways. In the district of Ramenki, in the Moor frog is observed a high variability and low correlation of morphogenetic processes (Fig. 2). 

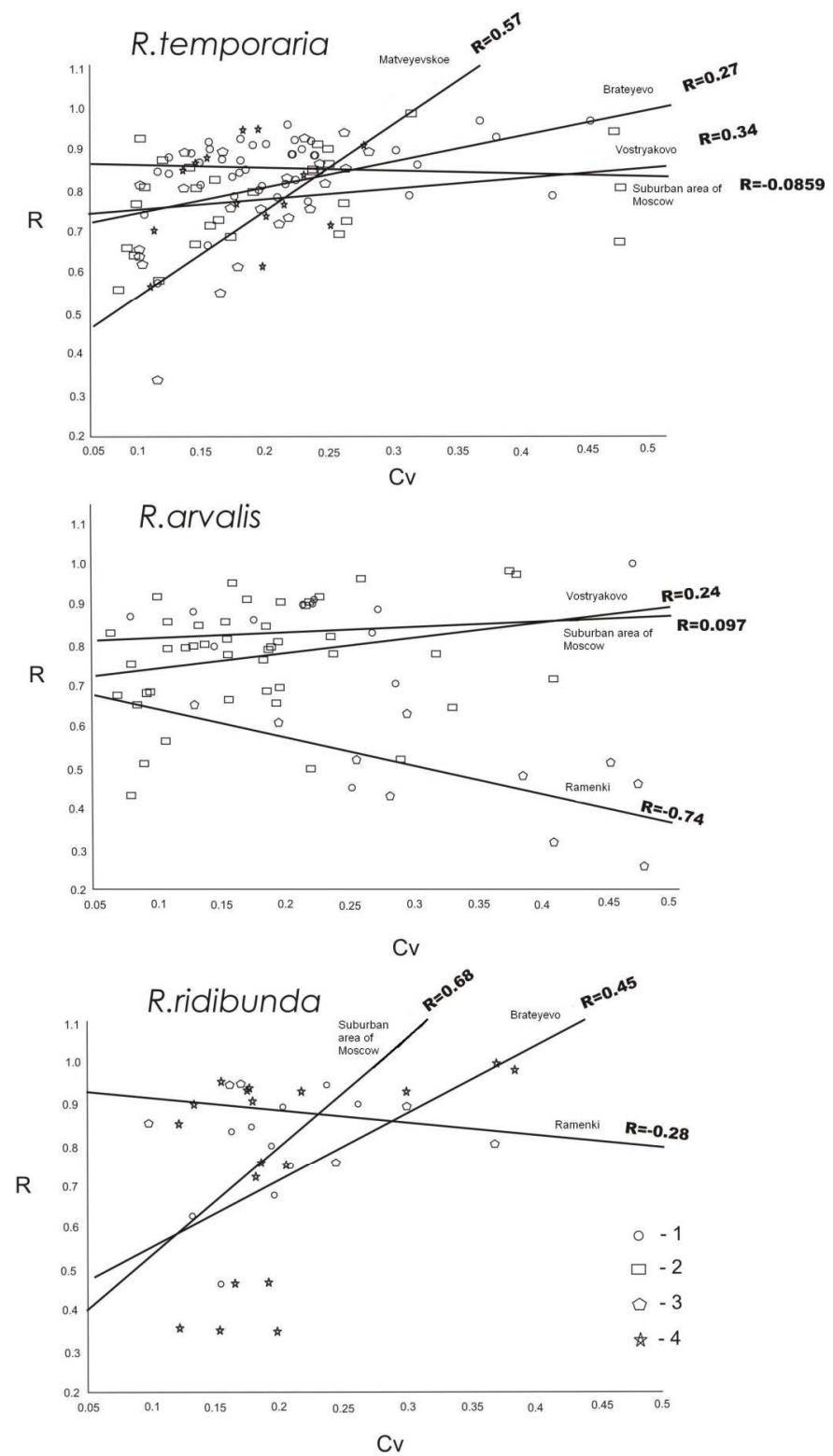

Fig. 2. Dependence of developmental variability $(\mathrm{Cv})$ of general correlation $\left(\mathrm{R}^{2}\right)$ for clutches from: 1 - Suburban areas of Moscow; 2 - Vostryakovo area; 3 - Ramenky area or Matveyevskoe area; 4 - Brateyevo area.

In the first place at the end of gastrulation comes the preparation for the neurulation processes, up to heterochronies, when the yolk plug has not disappeared yet, but it's not just the formation of the neural plate, but the rise of the neural crest (Fig. 3). 

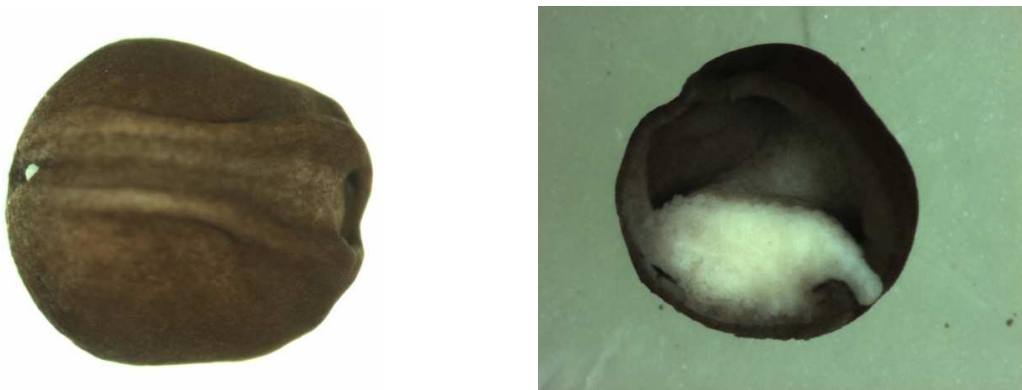

Fig. 3. Embryos of Common frog in 22nd stage with unclosed blastopore.

However, this accelerated development of high variability and miscorrelation leads to high mortality (about 5 times more in Moscow, compared with the population living outside the city of Moscow, which is characterized by low levels of anthropogenic pollution). In the Marsh frog in the district of Ramenki, the low overall correlation of development, compensates the large number of weakly inter-dependent processes. In the district Brateevo, in the Marsh frog is observed a combination of low variability and a high correlation (see Fig. 2), which allows embryos to grow more consistently and leads to low mortality. A somewhat different picture from Moor frog, living in the same area: with very low overall correlation of development, the key role is played by the ventral lip of blastopore screwing. A similar pattern was observed in embryos of the Common frog, which clutches were fixed from the pond, located $5 \mathrm{~km}$ downstream of the Setun river - in the district of Matveevskoe. In the Common frog gastrula, with high variability of the gastrulation processes, is observed a significant increase of the correlation among morphogenetic processes, ie with a correlation coefficient of less than 0.6 in the relationship between developing structures. This ensures the integrity of the eggs with the predominant role of the process of screwing in the ventral lip of blastopore.

The development of Common and moor frogs in the district of Vostryakovo varied. In the Common frog with a relatively low correlation of the general development, as well as in the district of Brateevo, an important role played the processes of changes in the diameter of eggs associated with the beginning of the neural elongation of the embryo. In the moor frog with a very high proportion of significance, but not high correlation coefficients between the studied traits is observed as a characteristic of gastrulation the predominance of the role on the ventral lip of blastopore invagination. In the eggs in gastrulation from nests near Moscow also significantly affects the overall high correlation of development in conjunction with their low variability (see Fig. 2). However, for the eggs of the Common frog populations near Moscow, the dimensional characteristics are closely related to the amount of yolk in the eggs. To Moor and Marsh frogs, fixed at 17th stage, the predominant role is played by processes of the screwing of the ventral lip of blastopore.

As can be seen from the above analysis the changing nature of morphogenetic processes during early development in anurans is due to changes in the correlation of variability and correlation of the emerging structures. This is manifested by increasing the total number of interrelated features that allows to keep and maintain the integrity of the embryo and thus provide a clearer differentiation of developing structures, despite their high variability. The 
second possible way of regulating early ontogenesis is realized in the amplification of correlative linked structures formed precisely at the stage of investigation, coupled with the increasing variability of morphogenetic processes. As a result, the development of this structure is accelerated. An extreme version of such correlation of variability and correlation of development is the emergence of heterochronies, i.e. situation where the structures of the embryo is formed, advancing the general process of development. Our data show that the occurrence of heterochrony changes may occur as a result of a sharp drop of the general correlation of development, against the backdrop of significantly increased variability in the emerging structures. This leads to a significant increase in mortality and in the case of the population of the Ramenki district to its extinction, aside from the small number of this population.

No less important is the conclusion that, in spite of interspecific ecological and morphological differences between Common and Marsh frogs, the mechanisms of regulation of early development occur in a general scheme. This indicates a non-specific reactions of early embryogenesis. The differences in overall mortality between them, apparently due to a later spawning, characteristic of the Marsh frog. Its embryogenesis is under more favorable terms than those with Common frogs against a background of lower concentrations of pollutants.

\section{Adaptation of embryogenesis to a new environmental evolutionary factor - Is it possible?}

Modern concepts are based on the division of any sign of variability into three components: genetic, paratypic (environmental) and epigenetic. As the name implies, genetic variability is formed due to the work of the genotype, paratypic - is the result of the impact of external environmental factors on the ontogeny, and epigenetic variability appears as a result of interactions among cells, tissues, organs developing, so changes in one element leads to changes of many interacting structures and functions (Cherdantsev \& Scobeyeva, 1994; Horder, 2006, 2008). As shown by the few experimental data, the proportion of the genetic components of the total variability in the early stages of embryogenesis is not large and varies considerably in the investigated characteristics, depending on experimental conditions (Surova, 1988a; Travis, 1980, 1981; Berven, 1982; Berven \& Gill, 1983).

For example, in tadpoles of Rana silvatica of populations of the plains of Maryland, the mountains of Virginia and tundra of northern Canada, the heritability of growth rate is 0.08 , 0.58 and 0.27, respectively (Berven \& Gill, 1983). Our own calculation of the coefficient of heritability (in the broadest sense of the term) of a number of morphometric characters of Common frog embryos at the stage of hatching, showed that the average proportion of the genetic component is about $10 \%$. This allows us to consider the overall variability of the early embryonic stages as a combination of paratypic and epigenetic components of variability and to assess their contribution to the variability in development. To do this, we performed an experiment using the cross-combinations of two environmental factors: water chemistry and density of embryos per unit volume of water. At the same time as the other parameters are aligned (temperature, light, etc.). Eggs, collected in the natural ponds of Moscow, has evolved in the water from their home pond and water from the ponds, which 
are located outside the city of Moscow in an area with low anthropogenic load. Eggs from the ponds that are located outside Moscow has evolved in the water of the native ponds and water from the city's ponds. Because in the experiment were used clutches of Common frogs from Moscow ponds, placing these eggs in ponds from outside Moscow, for the chemical composition that is different from that in which live and breed frogs of urban populations for many generations, should not be considered as a control or optimal conditions. The second environmental factor - tadpoles density - is no less important. Of course, its impact is more significant in the later stages of development, when begins to operate the so-called "group effect" (Schwartz et al, 1976; Severtsov, 1996). However, even at stages of development before hatching, the cluster of eggs is also important because is a regulator of oxygen inside the cluster (Surova \& Severtsov, 1985). The results of factor analysis performed on the results of this experiment, allow us to conclude that the effect of the chemical composition of water and different densities of tadpoles have little impact on the overall morphogenesis. Plays a fundamental role the tempo of growth characteristics: an increase in the overall size of the larvae, depending on the stage of development that allow us to demonstrate that in the early development plays an important role the epigenetic component of variability.

The idea of epigenetic effect is to shape the developing embryo belongs to Huxley (1942) and developed by Waddington (1956). All stages of the development are potentially open to evolutionary changes, but as epigenetic interactions is so fundamental, early evolutionary stages are stable (Horder, 2006). These stages are called critical (Svetlov, 1978), nodal (Cherdantsev 2003), or even Phylotypic (Sander, 1983), as this stages may coincide with the conservative Haeckel's stages (Hall, 1997; Richardson, 1998). But is possible find a name such as "Korpergrundestalt" (Seidel, 1960), "Phyletic stage" (Cohen, 1977) "Zootip / Phylotype" (Slack et al., 1993), "Phylotypic period" (Richardson, 1995) "Hounglass model" (Duboule, 1994). However, the critical stages (or even critical periods of development) do not always coincide with the phylogenetic stages. Allocation of such stages in the development, usually is based on the idea of laying new structures of the embryo at this stage and determination of the fact that it is at these stages when is observed a high mortality of embryos.

Morphometric analysis of several successive stages of development showed that the duration of the critical stages may be limited to one or several consecutive stages - a critical period in development (Severtsova \& Severtsov, 2011). During these stages (period) value of the estimated coefficients of variation of traits in embryos from different nests are not significantly different. Between the critical periods, the variability can have high or low significance, characteristic of the critical period. This is clearly seen in the analysis of changes in the values of the coefficients of variation in egg, died during the experiment. To them were characteristic the values of the coefficients of variation above or below the critical value. Among the survivors clutches in the critical period of development was observed an increase in mortality and the occurrence of anomalies incompatible with life, but the proportion of those embryos was low and the clutch continues the development. The earliest nodal stage can be seen from 18 to 20 stage of development.

The second critical period in early embryogenesis involves stage after hatching, i.e. 32 - 33rd stage of development. This period is critical for the formation of the overall length of the 
embryo $(L o)$ and the length of the tail plate $(L x)$. At the same time, critical for the formation of the caudal plate width $(W x)$ is the stage 34, where there is a transition of tadpoles from attached to embryonic jelly coat (gallert) to free-swimming lifestyle. 36th stage of development is critical for the formation of signs of "length of the body» $(L b)$ and "long tail plate» $(L x)$, but not for the sign " total length of the embryo» $(L o)$. For the features that characterize the differentiation of the embryo were selected the following nodal stages: " length of the muzzle " $(D l)$ and "width of the head" $(W g)$ - 36th stage, for the feature "length of the head" (Dlg) - 34th stage, and for the feature "width of the sucker" $(W)$ - 33th stage of development. For other characters, Vis, $H, R$, and eye, - the allocation of nodal stages in the investigated interval of development is difficult. Perhaps, all the investigated features of the critical period are present even in the 39th stage of development, but to confirm this fact, studies should be undertaken at more advanced stages of development. Thus, in the development the critical periods can be distinguished, but these periods are critical not only for the development of the embryo as a whole, but also for the process of formation of its individual structures. In some cases, these periods can be the same for different structures and then a group is formed ("modules") signs, that changes the correlation between "variability - correlation" which is similar. Thus, the signs of the first group, $L o, L b, L x$ and $W x$, describing the growth processes exhibit insignificance, with the development, reduced the general variability with a significant increase of the correlation (Fig. 4).

At the same correlation of growth processes sharply increases from 29 to 32 stage and 34 to 36th, i.e. just to pre-nodal and nodal stages. Signs that do not have the segment of the nodal stage (Vis, $H, R$, and eye) are characterized by an increase in the variability of development and low coherence. In signs $(\mathrm{Dl}, \mathrm{Dlg}, \mathrm{Wg}, \mathrm{W})$, for which was isolated nodal stage, with low variability increases, anyway there is an increase in the coherence of development. Our findings are confirmed by other researchers, which also showed that the so-called Phylotypic stages of development increases the level of morphological interactions by a decline in variability (Irmler et al., 2004), and such stage is also characterized by modularity (Raff \& Sly, 2000; Galis \& Metz, 2001; Galis \& Sinervo, 2002).

It is shown that modularity acts as a buffer mechanism for deviant development in extreme environments (Schmidt \& Starck, 2010). Thus, influencing on the signs themselves, the environment does not change the modularity of its structure. Only when the impact causes an increase in the variability of development, there is either independent development units (up to the emergence of heterochronies (Richardson, 1995), or the emergence of new correlation coefficients between the modules and, consequently, the formation of a unified system of non-rigid correlation interactions. (Severtsova \& Severtsov, 2011).

In a variety of environmental conditions the extent to which you can change a sign, is limited by its norm of reaction. This term was proposed by I. I. Schmalhausen (1969) and is special an individual characteristic, reflecting the breadth of variability in body shape in response to exposure to the environment and the ongoing without changing its genotype (Severtsov, 2004).

In the english-language evolutionary studies, the concept of norm of reaction criterion is close to the concept of "phenotypic plasticity" (Gordon, 1992; Via et al., 1995; Pigliucci, 2005; Garland \& Kelly, 2006). As wider is the norm of reaction of genotype, wider is the variation of sign limits and is wider the range of environmental conditions in which this feature 
ensures the survival of the individual. It is in unstable conditions where the individual with the most wide norm of reaction will get a selective advantage (Severtsov, 1985; Severtsov \& Surova, 1981).
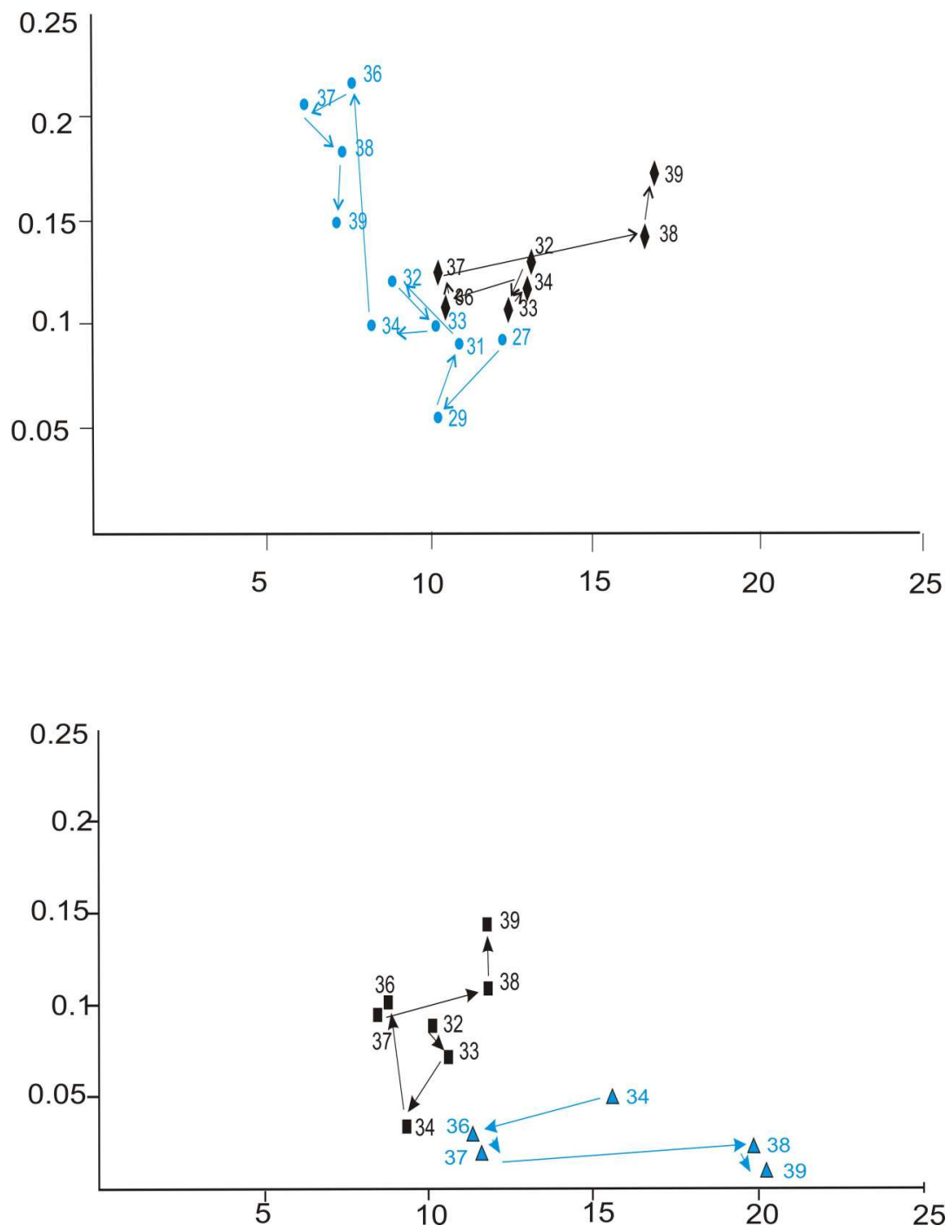

Fig. 4. Stepwise analysis of change in values of a generalized coefficient of determination $\left(C v_{\text {общ) }}\right.$ (axis $\mathrm{X}$ ) from determination coefficient $\left(R^{2}\right)$ (axis $\mathrm{Y}$ ). Numbers means the stage number. For signs: • - Lo, $L b, L x, W x$ and $\bullet-D l, V i s, W g, D l g, W, H, R$, eye. For signs: - - for signs $\mathrm{Dl}, \mathrm{Wg}, W, \mathrm{Dlg}$ and $\boldsymbol{\Delta}$-for signs Vis, $H, R$, eye. 
Mechanisms of "retention" of the formation of character in this framework for early embryogenesis practically have not been studied. In our works we have considered as a possible regulatory mechanism the changing of the correlation of the variability and consistency (correlation) of the formed structures. This is manifested by increasing the total number of interrelated features that allows to keep and maintain the integrity of the embryo's development and thus provide a clearer differentiation of developing structures, despite their high variability. The second possible way of regulating early ontogenesis is realized by the amplification of correlative linked structures, formed precisely at the stage of investigation, coupled with the increasing variability of morphogenetic processes. As a result, the developmental process of this structure is accelerated up to the emergence of heterochronies. Perhaps this way of regulation can be illustrated by a moving ball in the trench chreod in the model of epigenetic landscape proposed by Waddington (1947) (Shishkin, 1984).

If we consider the ball as a separate character state, not as a body (in the original model) then the path traveled by the ball-sign would be the way of development for this sign. In a stable environment occurs the moving of the ball on the bottom of the "trench" and we, analyzing the variability of this path, will see that it is not high. In the case of "interference" occurs "swing" of the ball in the trench chreod and thus an increase in the variability of the characteristic (Fig. 5). In this case we need constant adjustment the path of development that holds "the ball" in the trench, which will be implemented by changing the consistency of development of a specific sign with other signs of the developing embryo. But we should not forget that epigenomics has no additive genetic component, so the variability in developing systems is characterized by stability and equifinality (Schmalhausen 1942; Shishkin, 1984; Cherdantsev, 2003).

In this form of organization of morphogenetic variability the direct action of natural selection on early signs of morphogenesis is hampered. By itself, the variability of development can not be used as material for selection, because it's basically epigenomic and also is lost on the nodal stages of development. However, this does not mean that the adaptive evolution of the early stages of ontogeny to the effects of pollutants is not possible (Holloway et al., 1990; Forbes \& Calow, 1997), although in many cases, the rate of environmental change might be too quick to create adaptations (Lynch \& Lande, 1993; Burger \& Lynch, 1997). However, published data show an increase in resistance to pollutants (Hesnar, 1995; Forbes \& Calow, 1997; Gu et al., 2000; Johanson et al., 2001) and even the direct effects of environment on gene expression (Morozova et al., 2006; Wittkopp, 2007).

In some cases, is shown the stability of embryogenesis to the action of pollutants in amphibians from populations living in conditions of water pollution by organic substances (Hecnar, 1995; Johansson et al., 2001; Severtsova, 2002) or strong acidification (Andren et al., 1989). Comparison of resistance to pollution by nitrates of two populations of Bufo americanus showed a higher tolerance for this type of pollution in populations that spends a long time under the action of nitrates (Hecnar, 1995). Studies in Sweden have shown that the more resistant to prolonged exposure to a solution of ammonium nitrate are frog eggs from the southern regions, where the concentration of nitrate in nature is higher than in the northern (Johansson et al., 2001). 


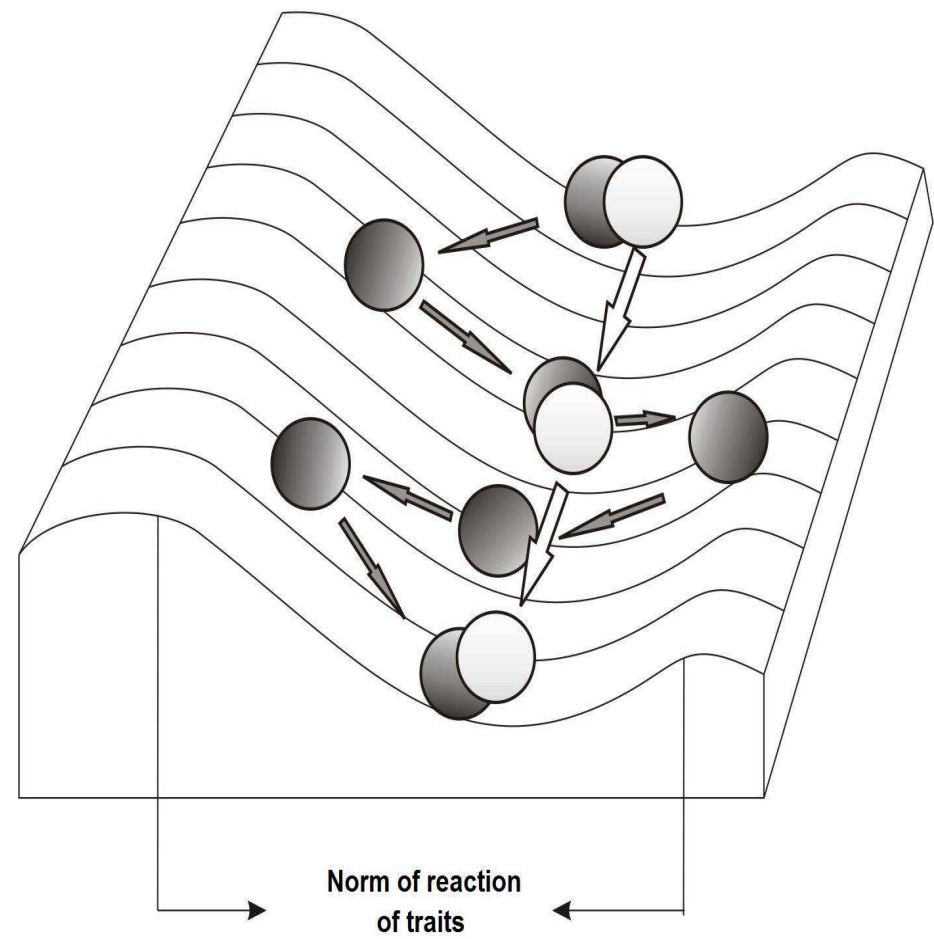

Fig. 5. Model of epigenetic landscape of Waddington (Shishkin, 1984)with changes. Plot of epigenetic landscape of the valley (chreod) which moves the ball, which symbolizes the path of the trait development. The chreoda's width is determinate by the norm of reaction of a trait, the depth, by the genetic determinism. Moving the light ball in the chreoda symbolizes the development of a trait in the right conditions, the dark ball, under adverse conditions that requiring regulation of development.

All these data indicate the possibility of adaptive evolution. Certainly, the formation of such adaptations are in all stages of the life cycle. However, as shown by the results, the factor analysis carried by us, according on the results of experiments with cross-coupling conditions for the development of tadpoles, response to exposure to the environment occurs individually for each clutch in each year of analysis (Severtsova, 2009). Consequently, the evolutionary transformation will occur at the level of change in the way of individual development of each clutch, driving changes in the way of development of each trait (WestEberhard, 2003).

\section{Conclusion}

In conclusion, we emphasize that our approach using morphometric analysis of early embryogenesis allow us to evaluate the general condition of the population, living in conditions of anthropogenic pollution of the environment and to answer the important question of the possible adaptations of early embryogenesis in this new evolutionary environmental factor. Variability- an inherent property of life. Variability is the material for 
natural selection and, therefore, the methodological approaches to the study of variability in understanding the degree of diversity and mechanisms of evolutionary changes have been well worked. Embryological studies dealing with the investigation of the features of ontogeny or evolutionary change of early development use morphometric approach for the study of variability in a lower grade.

\section{References}

Animals in conditions of anthropogenic landscape. (1990). Sverdlovsk ASUSSR UrO pp. 125. (Russ.).

Intraspecific variation in animal ontogenesis. (1980) M.: Nauka. pp 226 (Russ.).

Structure and functional role of animal populations in natural and transformed ecosystems. (2001) Abstract: I International Conference 17-20 September. Dnepropetrovsk. pp. 247. (Russ).

Allran, J. \& Karasov, W. (2000). Effects of atrazine and nitrate on northern leopard frog (Rana pipience) larvae exposed in the laboratory from posthatch through metamorphosis. Environ. Toxicol. Chem. V. 19, №.11, pp. 2850-2855.

Allran, J. \& Karasov, W. (2001) Effects of atrazine on embryos, larvae and adults of anuran amphibians. Environ. Toxicol. Chem. V. 20, №. 4, pp. 769-775.

Andren C., Marden M. \& Nilson G. (1989). Tolerance to low pH in a population of moor frogs, Rana arvalis, from an acid and a neutral environment: a possible case of rapid evolutionary response to acidification. Oikos. V. 56, pp. 215-223.

Beattie R.C., Aston R.J. \& Milner A.G .P. (1991)A Field-Study of Fertilization and Embryonic-Development in the Common Frog (Rana temporaria) with Particular Reference to Acidity and Temperature. J. of Applied ecology. V. 28, № 1, pp. 346-357.

Beattie R.S., Tyler-Jones R. \& Baxter M.J. (1992). Influence of pH, aluminum, temperature on embryonic development of Rana temporaria. J. Zool. V. 228. № 4. pp.557-570.

Beetschen, J.C. (2001). Amphibian gastrulation: history and evolution of a 125 year-old concept. Int J Dev Biol. V. 45, pp. 771-795.

Berven K.A. (1982). The genetic basis of altitudinal variation in the wood frog, Rana sylvatica. 1. An experimental analysis of larval development. Oecologia. v. 52. № 3. pp. 360369.

Berven K.A. \& Gill D.E. (1983). Interpreting geographic variation in life-history traits. Amer. Zool. v. 23. № 1. pp. 85-97.

Burger R. \& Lynch M. (1997). Adaptation and extinction in changing environments. In: Environmental stress, Adaptation and Evolution. Bijlsma R.; Loeschcke V. Springer Verlag, pp. 209-240.

Cherdantsev, V.G. \& Scobeyeva, V.A. (1994). The morphological basis of self-organization. Developmental and evolutionary aspects. RiVista di Biologyca- Biology forum. v. 87. № 1. pp. 57-85.

Cherdantsev, V. G. (2003). Morphogenesis and evolution. M. KMK. pp. 359 (Russ.).

Cohen, J. (1977) Reproduction. London: Butterworths.

Cooke A.S. (1974). The effect of pp'-DDT on adult frog (Rana temporaria). Brit. J. Herp. №4. pp. 647-652.

Dawson, D.A., McCormick, C.A. \& Bantle, J.A. (1985). Detection of teratogenic substances in acidic mine water samples using the frog embryo teratogenesis assay - Xenopus (FETAX). J. Appl. Toxicol. V. 5. № 4. pp. 234-44. 
Duboule, D. (1994) Temporal colinearity and the phylotipic progression: a basis for the stability of a vertebrate Bauplan and the evolution of morphologies through heterochrony. Dev Suppl pp. 135-142.

Dunson, W.A., Wyman, R.L. \& Corbett, E.S. (1992) A symposium of amphibians declines and habitat acidification. J. Herpetol. V.26. pp. 349-352.

Ettler, V., Mihaljevič, M., Matura, M., Skalová, M., Šebek, O. \& Bezdička P. (2008). Temporal Variation of Trace Elements in Waters Polluted by Municipal Solid Waste Landfill Leachate. Bulletin of Environmental Contamination and Toxicology. V. 80, №3, pp. 274279.

Falconer, D. (1981) Introduction to qualitative genetics. M.: Agropromizdat. pp. 486 (Russ).

Fetax. (1991). Standard guide for conduction the frog embryo teratogenesis assays- Xenopus (Fetax). Amer. Soc.for test. and mat. pp. 1-11.

Forbes, V.E. \& Calow, P. (1997). Responses of aquatic organisms to pollutant stress: theoretical and practical implications. In: Environmental stress, Adaptation and Evolution. Bijlsma R. \& Loeschcke V. B: Springer Verlag. pp. 25-42.

Fort, D.J., Guiney P., Weeks, J., Thomas J., Rogers, R., Noll, A. \& Spaulding, C. (2004). Effect of Methoxychlor on Various Life Stages of Xenopus laevis. Toxicological sciences. V. 81, pp. 454-466.

Freda, J. (1986). The influence of acidic ponds water on amphibians: A review. Water Air Soil Poll. V. 20. pp. 439-450.

Galis, F. \& Metz, J.A. (2001). Testing the vulnerability of the phylotipic stage: on modularity and evolutionary conservation. J exp Zool (Mol Dev Evol). V. 291, pp. 195-204.

Galis, F., \& Sinervo, B. (2002). Divergence and convergence in early embryonic stages of metazoans. Contrib Zool. V. 71, pp. 101-113.

Garland, T. \& Kelly, S. A. (2006). Phenotypic plasticity and experimental evolution. J. Exp. Biol. V. 209. pp. 2344-2361.

Gilbert, S. (1993).Developmental Biology. T. 1. M.:Mir. pp. 110-144. (Russ.).

Glukhova, E.V. \& Cherdantsev V.G. (1999) Microfolds in suprablastopore zone o frog's gastrula and its relation to mechanics and geometrics of the gastrula. Ontogenez. V. 30. № 6. pp. 369-379. (Russ.).

Gordon, D.M. (1992). Phenotypic plasticity. In keywords in evolutionary biology. Cambridge, MA: Harvard University Press. pp. 255-262.

Greenhouse, G. (1976). The evaluation of toxic effects of chemicals in fresh water by using frog embryos and larval. Environ. Poll. V.11. №4. pp. 303-315.

Gu, Y.Z., Hogenesch, J.B. \& Bradfield C.A. (2000). The PAS superfamily: sensors of environmental and developmental signals. Annu. Rev. Pharmacol. Toxicol. V.40. P.519-561.

Hall, R.J. \& Henry P.F.P. (1992). Assessing effects of pesticides on amphibians and reptiles: status and needs. Herpetol. J. V. 2. pp. 65-71.

Hall, B.K. (1997). Phylotypic stage or phantom: is there a highly conserved embryonic stage in vertebrates? Trends Ecol Evol. V. 12. pp. 461-463.

Hecnar, S.J. (1995). Acute and chronic toxicity of ammonium nitrate fertilizer to amphibians from southern Ontario. Environ. Tox. and Chem. V.14. pp. 2131-2137.

Holloway, G.J., Sibly, R.M. \& Pover, S.R. (1990). Evolution in toxic stress environments. Funct. Ecology. V. 4. pp. 289-294. 
Horder, T.J. (2006). Gavin Rylands de Beer: how embryology foreshadowed the dilemmas of the genome. Nat Rev Genet. V. 7. pp. 892-898.

Horder, T. (2008). A history of evo-devo in Britain. Theoretical ideals confront with biological complexity. Ann Hist Phil Biol. V. 13 pp. 101-174.

Horne, M.T. \& Dunson W.A. (1995). Toxicity of metals and low $\mathrm{pH}$ to embryos and larvae of the Jefferson salamander, Ambystoma jeffersonianum. Arch. Environ. Contam. Toxicol. V. 29. pp. 110-114.

Huxley, J.S. (1942). Evolution: The modern synthesis. London, pp. 74.

Irmler, I., Schmidt, K. \& Starck, J.M. (2004). Developmental variability during early embryonic development of zebra fish, Danio rerio. J exp Zool B: Mol Dev Evol. V. 302 pp. 446-457.

Johansson, M., Rasanen, K. \& Merila J. (2001). Comparison of nitrate tolerance between different populations of the common frog, Rana temporaria. Aquatic Toxicol. V. 54. pp. 1-14.

Leontieva, O. A. \& Semenov D. V. (1997). Amphibians as bioindicators of anthropogenic change in environment. Uspeji Sobrem. Biologii. T. 117. No. .6. pp. 726-736. (Russ.).

Lynch, M. \& Lande, R. (1993). Evolution and extinction in response to environmental change In Biotic Interactions and Global Change. Eds. Kareiva P.; Kingsolver J. \& Huey R.Sinauer Associates, Inc. Sunderland. MA. pp. 234-250.

Moller, A.P. \& Swaddle, J.P. Asymmetry, developmental stability, and evolution. Oxford: University Press, pp. 1997. 291.

Morgan, M. K., Scheuerman, P.R., Bishop, C.S. \& Pyles, R.A. (1996) Teratogenic potential of atrazine and 2,4-D using FETAX. J. Toxicol Environ Health. V. 48(2). pp. 151-168.

Morozova, T. V., Anholt, R. R. \& Mackay, T. F. (2006). Transcriptional response to alcohol exposure in Drosophila melanogaster. Genome Biol. V. 7. pp. 95.

Opitz, R., Braunbeck, T., Bögi, C., Pickford, D.B., Nentwig, G., Oehlmann, J., Tooi, O., Lutz, I. \& Kloas, W. (2005). Description and initial evaluation of a Xenopus metamorphosis assay for detection of thyroid system-disrupting activities of environmental compounds. Environ Toxicol Chem. V. 24(3) pp.653-64.

Orton, F., Carr, J.A. \& Handy, R.D. (2006). Effects of nitrate and atrazine on larval development and sexual differentiation in the northern leopard frog Rana pipiens. Environ Toxicol Chem. V. 25(1) pp. 65-71.

Pigliucci, M. (2005). Evolution of phenotypic plasticity: where are we going now? Trends Ecol. Evol. V. 20. pp. 481-486.

Raff, R.A. \& Sly, B.J. (2000). Modularity and dissociation in the evolution of gene expression territories in development. Evol Dev. V. 2 pp. 102-113.

Richardson, M.K. (1995). Heterochrony and the phylotypic period. Dev Biol. V. 172, pp. 412421.

Richardson, M.K., Minelli, A., Coates, M. \& Hanken J. (1998). Phylotypic stage theory. Tree. V. 13. № 4. pp. 158.

Saber, D.A. \& Dunson W.A. (1978). Toxicity of bog water to embryonic and larval anuran amphibians. J. Exp. Zool. V. 204. № 1. pp. 33-34.

Sander, K. (1983) The evolution of patterning mechanism: gleaning from insect embryogenesis and spermatogenesis. In: Development and Evolution. Goodwin, B.C.; Holder, N. \& Wylie, C.C. editors. Cambridge University Press, Cambridge. pp. 123159 
Schmalhausen I. I. (1942) Organism as a whole in individual and hitorical development. M.; L. AS USSR. pp. 212. (Russ.).

Schmalhausen, I. I. (1969) Problems of Darwinism.L. Nauka. pp. 492. (Russ.).

Schmidt, K. \& Starck, J.M.. (2010). Developmental plasticity, modularity, and heterochrony during the phylotypic stage of the zebra fish, Danio rerio. J Exp Zool B Mol Dev Evol. V. 15 № 314(2), pp. 166-78.

Schwartz, S.S., Pyastolova, O.A., Dobrininskaya, A.A. \& Runova, G.G. (1976). Group effect in populations of aquatic animals and chemical ecology. M.:Nauka. pp. 1-152 (Russ.).

Seidel, F. (1960). Korpergrundgestalt und Keimstruktur. Eine erorterung uber die Grundlagen der vergleichenden und experimentellen Embryologie und deren Gultigkeit bei phylogenetischen Uberlegungen. Zool Anz. V. 164 pp. 245-305.

Severtsov, A.S. (1985). Emergence of plastic features in phenotype under selection. Zhurnal obshei biologii. T. 46. № 5. pp. 579-589. (Russ.).

Severtsov, A.S. (1996). Group selection as a cause of emergence group adaptations. Zoologichesky zhurnal. T 75, No. 10, pp. 1525-1540. (Russ.).

Severtsov, A.C. (2004) Theory of evolution. Vlados. pp. 380. (Russ.).

Severtsov, A.S. \& Surova, G.S. (1981). Individual variability o norm of reaction and adaptation of population. Zhurnal obshei biologii T XLII, №2, pp. 181-192. (Russ.).

Severtsova, E.A. (2002) Adaptive processes and variability of embryogenesis of anuran amphibians in urban populations. Synopsis PhD thesis M.: MSU. 2002. 24 p russ.

Severtsova, E.A. (2005). Adaptation of Amphibian gastrulating embryos to an influence of anthropogenic pollution. 10 $10^{\text {th }}$ congress European Society for Evolutionary Biology. Poland. 15-20.08.2005. pp.514.

Severtsova, E.A. (2009). Experimental work on the correlation of variability components of development of Common frog tadpoles (Rana temporaria, Anura, Amphibia) in hatching stage. Zoologichesky zhurnal T 88, №1, pp. 1-10. (Russ.).

Severtsova, E.A. \& Severtsov, A.C. (2005). Interpopulation comparison of variability o gastrulation of Common frog embryos living in conditions of anthropogenic polluted ponds. Ontogenez. T. 36. №2. p. 110-122. (Russ.).

Severtsova, E.A. \& Severtsov, A.C. (2007). Interpopulation comparison of gastrula of Moor and Marsh frogs living in conditions of anthropogenic polluted ponds. Ontogenez. T. 38. № 1. pp. 1-14. (Russ.).

Severtsova, E.A. \& Severtsov A.C. (2011). Crucial stages of embryogenesis of R.arvalis Part 1: Linear Measurements of Embryonic structures. Russian Journal of Developmental Biology. Vol. 42, № 5, pp. 331-341.

Shishkin. (1984). Individual development and natural selectionp. Ontogenez. T. 15. № 2. pp. 115-136. (Russ.).

Slack, J.M.., Isaacs, H.V., Johnson, G.E., Lettice, L.A., Tannahill, D. \& Thompson J. (1992). Specification of the body plan during Xenopus gastrulation: dorsoventral and anteroposterior of the mesoderm. Dev. Suppl. V. 1. pp.143-149.

Slack, J.M.., Holland, P.W. \& Graham C.F. (1993). The zootype and the phylotypic stage. Nature, V. 361, pp. 490-492.

Sparling, D.W., Linder, G. \& Bishop C.A. (2001). Ecotoxicology of amphibian and reptiles. SETAC press. Pensacola. FL.

Stroganov, N.N. (1971). Methods for determinate the toxicity in aquatic environments . In Methods for biological research in aquatic toxicology. M.: Nauka.. pp. 14-60. 
Svetlov. (1978). Physiology (mechanics) of development. L.: Nauka, T.1. Processes of morphogenesis in cellular and organismic levels. 279 p. T.2. Internal and external actors of development. $263 \mathrm{p}$.

Surova, G. (1988). Interaction of tadpoles of Common frog in natural conditions. Ekologiya № 4. pp. 49-54.

Surova, G. (1988a). Environmental and hereditary components of periods of ontogenesis of Common (Rana temporaria) and Moor (R. arvalis) frog tadpoles. Zool Zhur T. 67.No. 3. pp. 396-405. (Russ.).

Surova, G. \& Severtsov A.C. (1985). Death in Common frog (Rana temporaria L.) in early ontogenesis and factors of it cause. Zool. Zhur. T. 44. No. 1, pp. 61-71. (Russ.).

Travis, J. (1980). Genetic variation for larval specific growth rate in the Hyla gratiosa. Growth. V. 44. № 3. pp. 167-181.

Travis, J. (1981). Control of larval growth variation in a population of Pseudacris triseriata (Amura:Hylidae). Evolution. V. 35. № 3. pp. 424-432.

Vershin, V.L. (1997) Ecological features in amphibian populations of urban territories. Synopsis: Doctoral degree thesis. Ekaterinburg: Institute of plant and animal ecology UrORAS pp. 47.

Via, S., Gomulkiewicz, R., De Jong, G., Scheiner, S. M., Schlichting, C. D. \& Van Tienderen, P. H. (1995). Adaptive phenotypic plasticity: consensus and controversy. Trends Ecol. Evol. V. 10. pp. 212-217.

Voronova, L.D., Golichenkov, V.A., Popov, D.V., Kalistratova, E.N. \& Sokolova Z.A. (1983). Reaction of pigmentary system of amphibian tadpoles in lower concentrations of some pesticides. In Problems of ecological monitoring and ecosystem model. L. Gidmeteoizdat . T. VI. pp. 77-90. (Russ.).

Waddington, C.H. (1947). Organizers and genes. M.: Gos. Izdat. Inostran. Lit. pp. 240. (Russ).

Waddington, C.H. (1956). Principles of Embryology. Allen \& Unwin, London.

West-Eberhard. (2003). Developmental Plasticity and Evolution. N. Y.: Oxford University Press. pp. 794.

Wittkopp. (2007) Variable gene expression in eukaryotes: a network perspective. J. Exp. Biol. V. 210. pp. 1567-1575.

Zakharov, V.M. (1989). Future prospects for population phenogenetics. Sov. Sci. Rev. Physiol. Gen. Biol. V.4. pp.1-79. 


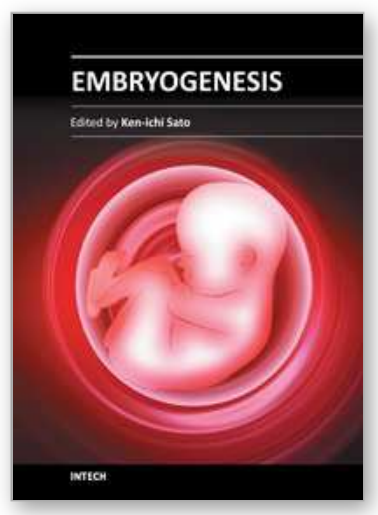

\author{
Embryogenesis \\ Edited by Dr. Ken-Ichi Sato
}

ISBN 978-953-51-0466-7

Hard cover, 652 pages

Publisher InTech

Published online 20, April, 2012

Published in print edition April, 2012

The book "Embryogenesis" is a compilation of cutting edge views of current trends in modern developmental biology, focusing on gametogenesis, fertilization, early and/or late embryogenesis in animals, plants, and some other small organisms. Each of 27 chapters contributed from the authorships of world-wide 20 countries provides an introduction as well as an in-depth review to classical as well as contemporary problems that challenge to understand how living organisms are born, grow, and reproduce at the levels from molecule and cell to individual.

\title{
How to reference
}

In order to correctly reference this scholarly work, feel free to copy and paste the following:

Elena A. Severtsova, David R. Aguillón Gutiérrez and Aleksey S. Severtsov (2012). Morphometry as a Method of Studying Adaptive Regulation of Embryogenesis in Polluted Environments, Embryogenesis, Dr. Ken-Ichi Sato (Ed.), ISBN: 978-953-51-0466-7, InTech, Available from:

http://www.intechopen.com/books/embryogenesis/morphometry-as-a-method-of-studying-the-adaptiveregulation-of-embryogenesis-in-polluted-environment

\section{INTECH}

open science | open minds

\section{InTech Europe}

University Campus STeP Ri

Slavka Krautzeka 83/A

51000 Rijeka, Croatia

Phone: +385 (51) 770447

Fax: +385 (51) 686166

www.intechopen.com

\section{InTech China}

Unit 405, Office Block, Hotel Equatorial Shanghai

No.65, Yan An Road (West), Shanghai, 200040, China

中国上海市延安西路65号上海国际贵都大饭店办公楼405单元

Phone: +86-21-62489820

Fax: +86-21-62489821 
(C) 2012 The Author(s). Licensee IntechOpen. This is an open access article distributed under the terms of the Creative Commons Attribution 3.0 License, which permits unrestricted use, distribution, and reproduction in any medium, provided the original work is properly cited. 